\title{
Assessment of the Response to an Experimental Dose of Furosemide in Patients with Decompensated Chronic Liver Disease and Ascites
}

\author{
Mohammad S. Khedr', Mohammad F. Hassan ${ }^{2 *}$, Mohammad A. Al-Shatouri, \\ Hanaa E. Ali'
}

${ }^{1}$ Internal Medicine Department, ${ }^{2}$ Endemic \& Infectious Diseases Department, ${ }^{3}$ Radiology Department, Faculty of Medicine, Suez Canal University, Egypt

\begin{abstract}
Background: Ascites due to cirrhosis can be mobilized with a treatment regimen consisting of dietary sodium restriction and oral diuretics. Ascites resistant to diuretic therapy requests adopting balanced approaches in its management but treatment responses are variable and frequently difficult to assess. Aim: To quantify response to an experimental dose of furosemide in patients with decompensated chronic liver disease and ascites. Subjects and Methods: a pre-post intervention study was carried out on 110 patients with ascites grade 2 or 3 receiving IV furosemide, and response was assessed by Absolute and percentage weight loss, the average daily weight loss, average daily urine output and \% deviation from the pre-intervention 24-h output, 24h urinary sodium, and fractional excretion of sodium. Results: our study revealed that $42.7 \%$ were responders to furosemide, and presence of moderate positive significant correlation between average daily urine output and average daily weight reduction $(r=0.682)$, also there is significant relationship between baseline urinary sodium level and FENa and diuretic response. Conclusion: This study revealed that the median point for diuretic response using absolute weight loss is around $0.4 \mathrm{~kg}$ and average daily urine output around $1500 \mathrm{ml}$, and that there is significant correlation between $24 \mathrm{~h}$ urinary sodium and diuretic response.
\end{abstract}

Keywords: cirrhosis, urinary sodium, sodium retention, loop diuretics

\section{Introduction}

The development of ascites in the setting of cirrhosis represents a landmark in the natural history of cirrhosis, predicting a poor prognosis with $50 \%$ mortality within 3 years $^{(1)}$. Diuretics are constantly used in patients with advanced liver cirrhosis to mobilize the excess extracellular fluid and to reduce ascites. Multiple diuretic classes, including loop diuretics, are used to treat patients with liver disease, either individually or in combination with distally-acting diuretics $^{(2)}$. The pathogenesis of sodium retention, the most prevalent renal function abnormality of cirrhosis, is only partially known. In approximately one third of patients with ascites, sodium retention occurs 
despite normal activity of the renin-aldosterone and sympathetic nervous systems and increased circulating plasma levels of natriuretic peptides(3). Twenty-four-hour urinary sodium measurements are useful in patients with ascites related to portal hypertension in order to assess the degree of sodium avidity, monitor the response to diuretics, and assess compliance with $\operatorname{diet}^{(4)}$. Thus, sodium is the major determinant of extracellular fluid volume (ECFV). Despite its frequency, the term "diuretic resistance" remains inadequately defined. In general, failure to decrease the ECFV despite liberal use of diuretics is often termed diuretic resistance. So many researchers had focused on defining diuretic and natriuretic responsiveness based on change in body weight or urine output relative to the dose of furosemide administered. More technically, also diuretic resistance has been expressed as $\mathrm{FENa}+$ of $<0.2 \%(5)$.

\section{Subjects and Methods}

Study design: The present study was carried out as a pre- post intervention study. The work was carried out in Suez Canal university hospital. Study population: Patients of either sex with non-malignant chronic liver disease of any etiology who present to the outpatients' clinics of Suez Canal University hospitals who accepted to participate in the study was enrolled only if they were between 25 and 75 years of age and have grade II or III ascites. Exclusion criteria included evidence of systemic infection or spontaneous bacterial peritonitis, a mean arterial pressure less than 75 $\mathrm{mmHg}$, evidence of active GIT bleeding, evidence of hepatic encephalo-pathy, serum sodium <115 $\mathrm{mEq} / \mathrm{L}$ and serum potassium $<3.4 \mathrm{mEq} / \mathrm{L}$, serum creatinine more than 3.5 $\mathrm{mg} / \mathrm{dl}$, cannot stop diuretics for a diuretic wash-out period of 4 days. Study protocol: Study participants were scheduled for 1week elective admission for evaluation of the initial response to IV furosemide. A 4day diuretic-wash-out period was ensured beforehand. Pre-intervention measurements (were done within the 24 hours preceding first dose of furosemide): included: i) Sex, age (in years), and body weight (KG). ii) Blood pressure and mean arterial pressure. iii) Assessment of ascites (grade II or III), iv) 24-hour urine output. v) Twenty-four-hour urine sodium, urine creatinine and fractional excretion of sodium $\left(\mathrm{FeNa}^{+}\right)$. vi) Twenty Four-H urinary chloride content. vii) Serum creatinine, estimated GFR using MDRD formula, serum sodium and potassium. Over the subsequent 72 hours, patients continued receiving IV furosemide in the test doses shown below, while being regularly monitored for body weight and daily urine output. In addition, all patients received spironolactone in the fixed dose of $50 \mathrm{mg}$ BD. Initial response evaluated at the end of this period. Furosemide dosage: Daily iv dosage was determined according to serum creatinine levels and body weight as shown below: S. CR. < $1 \mathrm{mg} / \mathrm{dl}$ (60 mg), S. CR. $>1$ to <1.4 mg/dl: (80 $\mathrm{mg}$ ), S. CR. $>1.4-<1.8 \mathrm{mg} / \mathrm{dl}:$ (120 mg), S. CR. $>1.8$ to $<2.5 \mathrm{mg} / \mathrm{dl}:$ ( $160 \mathrm{mg})$ and S.CR. $>2.5$ to $3.5 \mathrm{mg} / \mathrm{dl}$ : (200 mg). Diuretic treatment in the interim: In the interim (days 4, $5 \& 6$ ), patients were maintained on $150 \%$ of the initial furosemide doses, but they received the drug orally. Patients were kept using same doses of spironolactone. At day 7, patients received the same IV doses given above and sustained response was evaluated. At the end of day 3 and day 7, 24hour urinary sodium and chloride and fractional excretion of sodium is repeated. Response to furosemide diuresis was evaluated by: 1Absolute and percentage weight loss at the end of each period. 2- The average daily weight loss. 3-Average daily urine output and \% deviation from the pre-intervention 24-h output. 


\section{Statistical analysis}

Data was analyzed to demonstrate the following: 1- Description of demographic, clinical and laboratory features of the studied patients at enrollment in the study. Continuous variables were described as mean \pm standard deviation and discrete variables as frequencies. 2- Plotting proportions of furosemide-induced diuresis (responsive/non-responsive) for different cut-off points of percent increase in urine output, at days 3 and 7. 3- Plotting proportions of furosemide response for different cut-off points of \% reduction in body weight, at days 3 and 7. 4- Deciding a composite cutoff point by contrasting plots of urine-output and body weight. 5- Scatter plots for daily change in urine output and body weight for responsive and non-responsive individual patients along the course of the experiment.

Table 1: Age, gender, and body weight in patients with chronic liver disease and ascites who were enrolled in this study $(n=110)$

\begin{tabular}{|c|c|c|}
\hline Characteristics & Frequency & Percent (\%) \\
\hline Age in years & & \\
$<45$ & 13 & $11.8 \%$ \\
$45^{-}$ & 64 & $58.2 \%$ \\
$>60$ & 33 & $30 \%$ \\
Mean \pm SD & $55.7 \pm 8.5$ & \\
\hline Gender & 61 & $55.5 \%$ \\
Male & 49 & $44.5 \%$ \\
Female & 63 & \\
Body weight in kg & & $57.3 \%$ \\
Mean \pm SD & $74.5 \pm 9.4$ & \\
\hline \multicolumn{2}{|c}{} \\
\hline
\end{tabular}

\section{Results}

One hundred and ten patients with chronic liver disease were enrolled in the study. Table (1) shows that the mean age of study participants was $55.7 \pm 8.5,55.5 \%$ of our patients were males, mean body weight was $74.5 \pm 9.4$. Roc curve was plotted to determine the different cutoff values for \% of increase in urine output in days 3 and 7 for diagnosis of furosemide-induced response (Figure 1). Area under the curve (AUC) was 0.9 and $P<0.001$. According to the curve, the best cutoff point was $50 \%$ of increase in urine output at day 3 and day 7 for diagnosis of response with $53.9 \%$ specificity, $89.3 \%$ sensitivity and $69.1 \%$ overall accuracy at day 3 , and $57.1 \%$ specificity, $95.7 \%$ sensitivity, and $73.6 \%$ over all accuracy at day 7 (Figure 1). ROC curve for different cutoff values for $\%$ of reduction in body weight in days 3 and 7 for diagnosis of diuretic response showed that Area under the curve (AUC) was 0.9 and $P<0.001$. According to the curve, the best cutoff point was $1 \%$ of decrease in weight at day 3 for diagnosis of response with $77.8 \%$ specificity, $58.1 \%$ sensitivity and $80.9 \%$ overall accuracy. The best cutoff point was $1.75 \%$ of decrease in weight at day 7 with $77.8 \%$ specificity, $78.7 \%$ sensitivity, and $78.2 \%$ over all accuracy (Figure 2 ). Table 3 shows the changes in urinary sodium level, urinary chloride level, and FENa along day $0,3, \& 7$ and between responders and non-responders and as the table shows there was a significant change across the 3 points with responders showing higher levels in urinary sodium level, urinary chloride level, and FeNa along day 3\&7. But there was a significant change with response at day $3 \& 7$ in urinary sodium and chloride and not with blood $\mathrm{pH}$ and 
FENa. Figure (3) showed moderate positive correlation between average daily urine output and average daily weight reduction $(r=0.682, p<0.001)$.

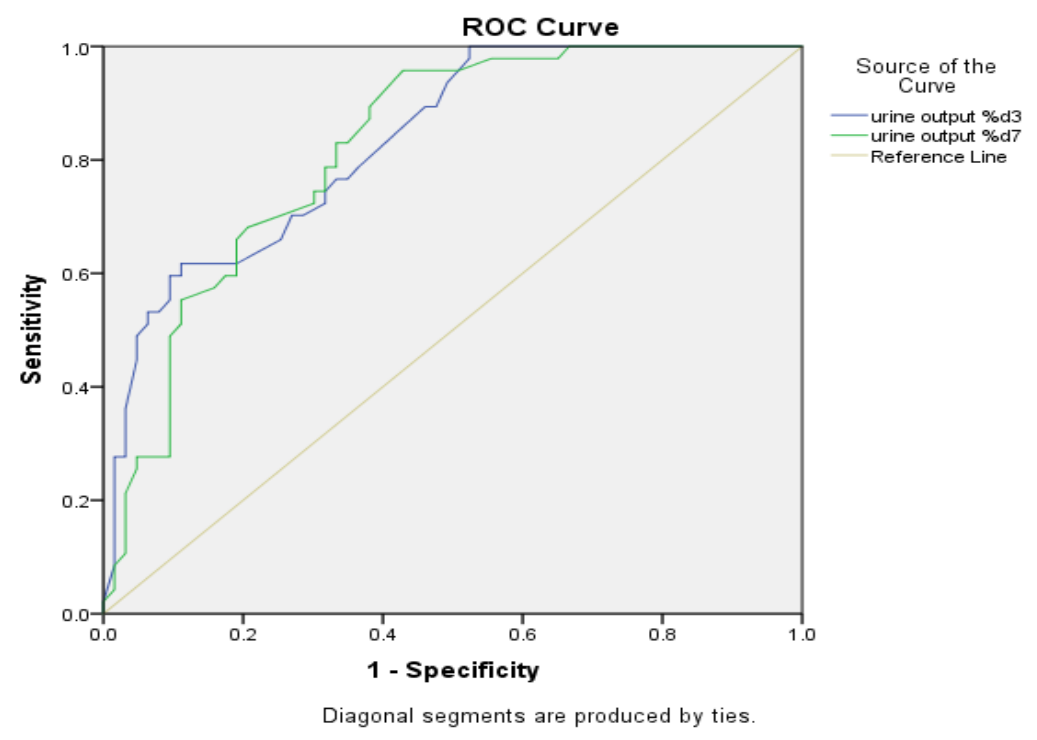

Figure 1: Roc curve for different cutoff values for \% of increase in urine output in days 3 and 7 for diagnosis of furosemide-induced response

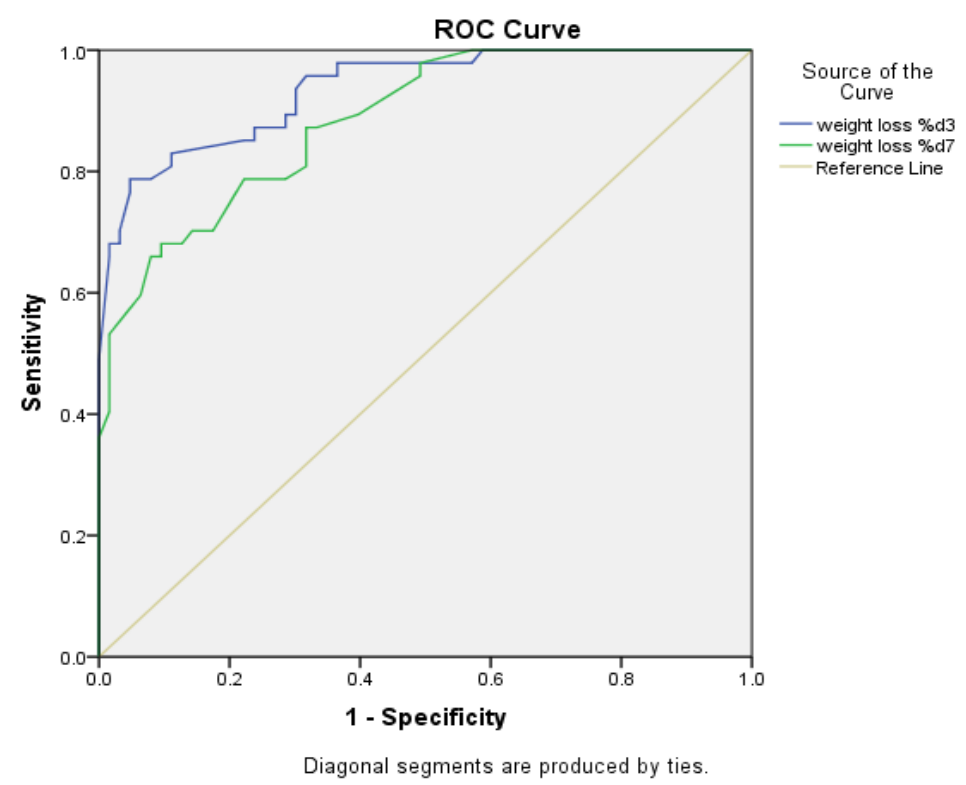

Figure 2: ROC curve for different cutoff values for \% of reduction in body weight in days 3 and 7 for diagnosis of diuretic response

\section{Discussion}

Many researchers had focused on defining diuretic and natriuretic responsiveness based on change in body weight or urine output relative to the dose of furosemide administered. In this study only 47 patients (42.7\%) were responders to furosemide with average daily urine output $1645 \mathrm{ml}$ and average daily weight loss $0.45 \mathrm{~kg}$. This comes in agreement with an analysis from ASCEND-HF study by Jozine et al, 2015, to assess diuretic response in acute heart failure patients which concluded that median diuretic response after 48 hours was -0.42 $\mathrm{kg} / 40 \mathrm{mg}$ furosemide (Interquartile range : 
$-1.0,-0.05 \mathrm{~kg} / 40 \mathrm{mg}$ furosemide) and median urinary diuretic response, based on urine volume after 24 hours per diuretic dose, was $1375 \mathrm{ml} / 40 \mathrm{mg}$ furosemide per 24 hours (6). Moreover Valente and his colleagues in 2014 founded that the median diuretic response was -0.38 (-0.80 to -0.13 ) $\mathrm{kg} / 40 \mathrm{mg}$ furosemide ${ }^{(7)}$. The higher prevalence of diuretic resistant ascites in this study can be explained by many reasons: firstly, all of our patients had severe cirrhosis (Child Pugh B or C) and ascites was grade 3 in majority (58.2\%) of our patients, secondly, we included patients with impaired kidney function, serum creatinine up to $3.5 \mathrm{mg} / \mathrm{dl}$. Also, in a study by Elbasel and others in Cairo University at 2015the prevalence of diuretics resistant ascites was $30 \%{ }^{(8)}$. Moreover, a Tunisian study included 124 cirrhotic patients, prevalence of resistant ascites was $21.8 \%(9)$. Studies used $24 \mathrm{~h}$ urinary sodium as indicator of diuretic response and to assess compliance to salt restriction.

Table 2: Laboratory findings of study participants before starting furosemide therapy

\begin{tabular}{|l|c|}
\hline Lab and radiological parameter & Mean \pm SD \\
\hline Urinary $\mathrm{Na}(\mathrm{mmol} / \mathrm{L})$ & $29.3 \pm 12.5$ \\
\hline Urinary $\mathrm{Cl}(\mathrm{mmol} / \mathrm{L})$ & $31.1 \pm 14.5$ \\
\hline Fe/Na $\%$ & $0.29 \pm 0.22$ \\
\hline S. Creatinine $(\mathrm{mg} / \mathrm{dl})$ & $1.1 \pm 0.51$ \\
\hline S. $\mathrm{Na}(\mathrm{mmol} / \mathrm{l})$ & $133.4 \pm 2.7$ \\
\hline S. K (mmoi/l) & $3.7 \pm 0.55$ \\
\hline eGFR (MDRD) & $79.5 \pm 47.8$ \\
\hline Average daily urine output (ml/day) & $1249.2 \pm 486.8$ \\
\hline
\end{tabular}

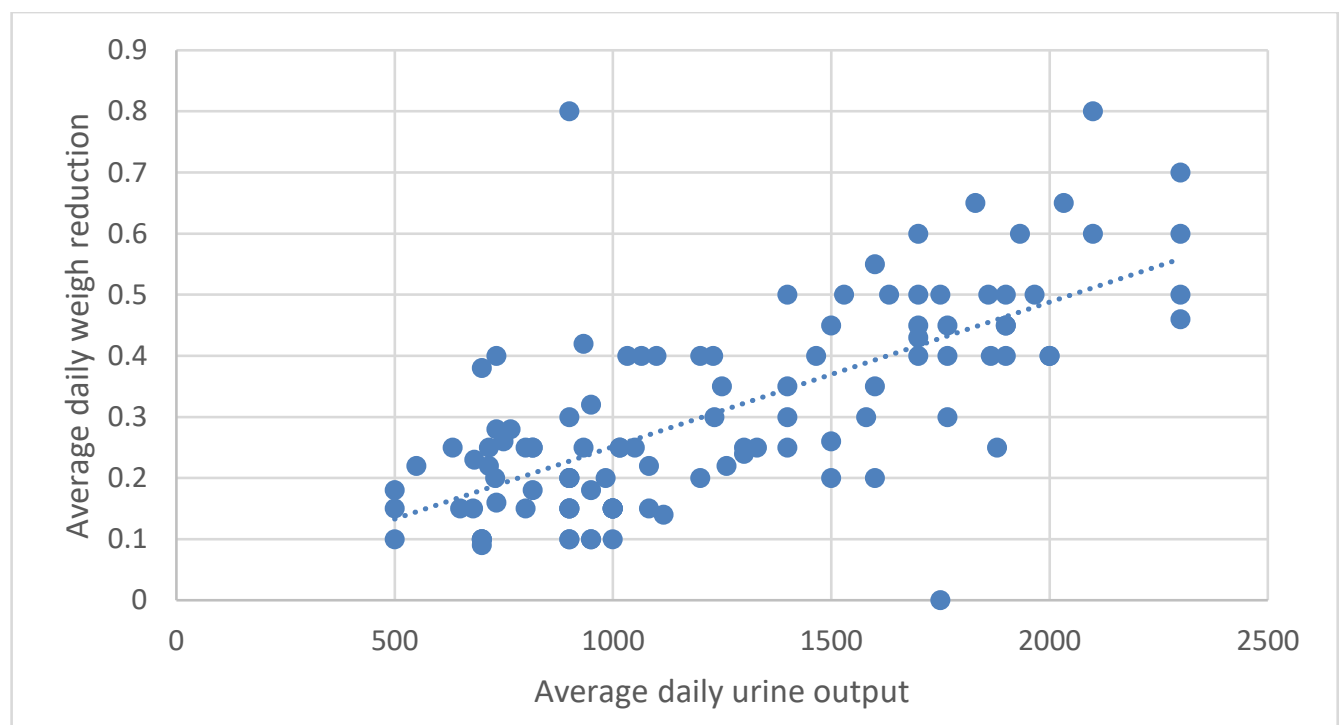

Figure 3: Correlation between average daily urine output and average daily weight reduction

Some studies considered $78 \mathrm{mEq}$ as cut off value for response (diuretic-resistant (with 24-h urinary sodium $<78 \mathrm{mEq}$ ) and diureticsensitive (with 24-h urinary sodium $\geq 78$ $\mathrm{mEq}^{(10)}$. The current study showed that there is a significant relationship between baseline urinary sodium level and FeNa and diuretic response This come in agreement with a study by Uojima et al (2017)(11) in which they used tolvaptan and diuretics in patients with liver cirrhosis and ascites and concluded that urinary sodium excretion 
was significantly higher in responders compared with non-responders (108.2 \pm 70.5 vs $42.6 \pm 36.7, p=0.0003)$. And multivariate analysis confirmed that urinary sodium levels were independent factor for response $(\mathrm{p}=0.0114$; hazard ratio, $0.9418 ; 95 \% \mathrm{Cl}$ )
This study revealed that the median point for diuretic response using absolute weight loss is around $-0.4 \mathrm{~kg}$ and average daily urine output around $1500 \mathrm{ml}$, with a significant correlation between 24 h urinary sodium and diuretic response.

\section{Conclusion}

Table 3: Urinary $\mathrm{Na}$, urinary $\mathrm{Cl}$ and FeNa levels among the 3 assessment points (day 0,3 , and 7) between diuretic responders and non-responders groups

\begin{tabular}{|c|c|c|c|}
\hline & $\begin{array}{l}\text { Responders } \\
\text { Mean } \pm \text { SD }\end{array}$ & $\begin{array}{c}\text { Non-responders } \\
\text { Mean } \pm \text { SD }\end{array}$ & $p$-value \\
\hline $\begin{array}{l}\text { Urinary sodium level } \\
\qquad \begin{array}{l}\text { U-Na level at day o } \\
\text { U-Na level at day } 3 \\
\text { U-Na level at day } 7 \\
\text { p-value }\end{array}\end{array}$ & $\begin{array}{c}23.3 \pm 8.8 \\
72.8 \pm 17.5 \\
75.2 \pm 15.4 \\
<0.002^{2^{*}}\end{array}$ & $\begin{array}{c}33.7 \pm 13.1 \\
58.9 \pm 11.9 \\
61.8 \pm 10.9 \\
<0.001^{2^{*}}\end{array}$ & $\begin{array}{l}<0.001^{1^{*}} \\
<0.001^{1^{*}} \\
<0.001^{1^{*}}\end{array}$ \\
\hline $\begin{array}{l}\text { Urinary chloride level } \\
\text { U-Cl level at day o } \\
\text { U-Cl level at day } 3 \\
\text { U-Cl level at day } 7 \\
\text { p-value }\end{array}$ & $\begin{array}{r}30.1 \pm 15.7 \\
77.4 \pm 15.6 \\
78.9 \pm 15.7 \\
<0.001^{2^{*}}\end{array}$ & $\begin{array}{c}31.9 \pm 16.8 \\
69.6 \pm 16.3 \\
70.8 \pm 15.7 \\
<0.001^{2^{*}}\end{array}$ & $\begin{array}{l}0.714^{1} \\
0.003^{1^{*}} \\
0.001^{1^{*}}\end{array}$ \\
\hline $\begin{array}{l}\text { FeNa } \\
\text { FeNa level at day } 0 \\
\text { FeNa level at day } 3 \\
\text { FeNa level at day } 7 \\
\text { p-value }\end{array}$ & $\begin{array}{c}0.22 \pm 0.18 \\
0.68 \pm 0.50 \\
0.69 \pm 0.43 \\
<0.001^{2^{*}}\end{array}$ & $\begin{array}{c}0.35 \pm 0.22 \\
0.62 \pm 0.35 \\
0.66 \pm 0.36 \\
<0.001^{2^{*}}\end{array}$ & $\begin{array}{c}<0.001^{1^{*}} \\
0.631^{1} \\
0.728^{1}\end{array}$ \\
\hline
\end{tabular}

1=Mann hitney U test; 2 . Friedman test; *Statistically significant at $p<0.05$.

\section{References}

1. Guevara M, Cárdenas A, Uriz J, et al. Prognosis in patients with cirrhosis and ascites. In: Ascites and Renal Dysfunction in Liver Disease: Pathogenesis, Diagnosis, and Treatment, Second Edition (2005). Chapter 21.

2. Gines P, Angeli P, Lenz K, et al. EASL clinical practice guidelines on the management of ascites, spontaneous bacterial peritonitis, and hepatorenal syndrome in cirrhosis. J Hepatol. 2010;53: 397-417.

3. Angeli P, Gatta A, Caregaro L, et al. Tubular site of renal sodium retention in ascitic liver cirrhosis evaluated by lithium clearance. Eur J Clin Invest. 1990; 20: 111-117.
4. Schrier RW. Renal sodium excretion, edematous disorders, and diuretic use, Philadelphia, Lippincott Williams \& Wilkins, 2010.

5. Brater DC. Update in diuretic therapy: clinical pharmacology. Semin Nephrol. 2011; 31(6):483-494.

6. ter Maaten JM, Dunning AM, Valente $M A$ et al Diuretic response in acute heart failure-an analysis from ASCENDHF. Am Heart J. 2015 170(2):313-21.

7. Valente $M$, Voors A, Damman K, et al. Diuretic response in acute heart failure: clinical characteristics and prognostic significance. Euro Heart $\mathrm{H}, 35$. 2014, 1284-1293.

8. El Basel M, El Mazny A, Emam A, et al. Diagnostic usefulness of the random urine $\mathrm{Na} / \mathrm{K}$ ratio in predicting therapeutic response for diuretics in cirrhotic 
patients with ascites. Kasr Aliny Med J. 2015; 21:60-65.

9. Ennaifer R, Elleuch $\mathrm{N}$, Romdhane $\mathrm{H}$, et al. Refractory Ascites in Cirrhosis: Prevalence and Predictive Factors. J Liver. 2014; 3:162.

10. El-Bokl MA, Senousy BE, El-Karmouty $\mathrm{KZ}$, et al. Spot urinary sodium for assessing dietary sodium restriction in cirrhotic ascites. World J Gastroenterol. 2009; 7, 15(29): 3631-3635.

11. Uojima $\mathrm{H}$, Kinbara $\mathrm{T}$, Hidaka $\mathrm{H}$, et al. Close correlation between urinary sodium excretion and response to tolvaptan in liver cirrhosis patients with ascites Hepatology Research. 2017; 47: E14-E21. 
